Geograficando, vol. 13, n. ${ }^{\circ}$ 2, e031, diciembre 2017. ISSN 2346-898X

Universidad Nacional de La Plata.

Facultad de Humanidades y Ciencias de la Educación.

Departamento de Geografía

\title{
Sassen, S. (2015). Expulsiones. Brutalidad y complejidad en la economía global (Trad. Stella Mastrangelo). Buenos Aires: Katz Editores. 249 páginas
}

\author{
Florencia Bertolotti
}

Universidad Nacional de Mar del Plata, Argentina | floren.bertolotti@gmail.com

Es sabido cómo el capitalismo, lejos de desaparecer, se expande; avanza y crea beneficios para algunos mientras excluye los de otros. Este carácter paradójico define y conduce al abordaje teórico de Saskia Sassen quien, en su destacada obra Expulsiones. Brutalidad y complejidad en la economía global, presenta nuevas preguntas para profundizar en la comprensión sobre las novedosas formas de operar del sistema económico mundial en el transcurso de los últimos veinte años. Desde entonces, el desarrollo aparentemente favorable de las nuevas lógicas del capitalismo contiene una ventana de conflictos que agudizan los procesos ya conocidos de pobreza, desigualdad y crisis. Por esto la autora, en una selección de casos ilustrativos, analiza los fenómenos de expulsión acontecidos en diferentes regiones del mundo, buscando en sus características más visibles los elementos sistémicos que les dan permanencia y de alguna manera los unen.

En relación a esto, y en línea con sus libros anteriores, Sassen produce un trabajo pretendiente de totalidad. Dicho carácter se pone de manifiesto en la introducción, instancia en la cual se presentan de modo general las ideas y preocupaciones que luego serán desarrolladas a lo largo de toda la obra. De este modo, a través de cuatro capítulos sobre temáticas dispares y lugares geográficamente diferentes pero potencialmente afectados por los nuevos conflictos socioeconómicos de la época, la autora se propone des-teorizar categorizaciones conceptuales familiares trazando un recorrido focalizado en los paralelismos entre los fenómenos. Esto requiere pensar más allá de las diferencias clásicas como Sur-Norte, capitalismo o comunismo, desarrollo y subdesarrollo, para dar significados sustanciales a los procesos implicados y no interpretarlos sólo como meros aumentos de casos nacionales excepcionales en términos de pobreza o responsabilidades estatales. Al mismo tiempo, las páginas iniciales presentan un desafío acerca de la necesidad de pensar bajo conceptos realmente vinculados a las características y agudezas de cada dinámica, que resultan "brutales” y “estructurales”, según lo planteado por la autora. Todo ello es realizado con éxito en los diferentes apartados, pero cobra un sentido mayor en el primer capítulo, extenso y detallado, núcleo fundamental del libro. Los apartados posteriores ilustran ejemplificativamente los desencadenantes de las lógicas explicadas en la 
primera instancia.

“Economías en contracción, expulsiones en expansión” titula al capítulo 1. En él, se describe un proceso iniciado a partir de la década 1980 cuando la creciente tercerización y financiarización de la economía empezaron a construir, en palabras de Sassen, "formaciones predatorias", las cuales profundizan la concentración de la riqueza en la parte superior de la escala social. A su vez, este tipo de capitalismo reproduce una característica común en sus desencadenantes: el crecimiento aumenta como nunca ante los mecanismos de expulsión en las sociedades. Se inicia así un movimiento cíclico y repetitivo en los diferentes rincones del mundo, a partir del cual los sectores financieros cobran mayor protagonismo en las decisiones, se endeudan cada vez más los gobiernos y el bajo crecimiento real de la economía se refleja en individuos atravesados por conflictos de escala política, económica y ambiental. En este sentido, el capítulo describe, por un lado, cómo el desarrollo concentra sus beneficios en las corporaciones y aumenta la desigualdad interna de los países, contenedores de nuevos desempleados, cuando no se encuentran oportunidades laborales en las ahora ciudades "polo" de trabajo. Por el otro, surgen nuevos desplazamientos geográficos en todo el mundo y se ve alterada la constitución de las urbes. Estos movimientos, en tanto problemática emergente, responden a la operación de las lógicas sistémicas y conectan al apartado con los capítulos siguientes, en los cuales son explicitados dichos causantes.

La explicación de estas lógicas sistémicas alcanza un claro desarrollo en el segundo capítulo, "El nuevo mercado global de tierras”. Todos los casos ejemplificativos seleccionados aquí -como la adquisición de vastas extensiones de tierra alteradas para el monocultivo- permiten entender, en primera instancia, la dimensión empírica de las prácticas corporativas a través de la compra de tierras en diferentes zonas del mundo y, en segundo término, la pérdida de protagonismo de los gobiernos democráticos, que viabilizan la práctica para dichos grupos de poder pero dependen cada vez de compromisos ciudadanos, como por ejemplo de los impuestos individuales. Estas economías nacionales debilitadas, como bien explica la autora, van definiendo "gobiernos-burguesía", los cuales ya no operan a favor de los pueblos desventajados por los sucesivos cambios sino en dependencia del accionar de las corporaciones. Se manifiesta de este modo el carácter paradójico del sistema, capaz de generar lógicas que operan independientemente de los estados y concentran inversiones en sectores privilegiados; lo cual produce manufacturas reducidas, territorios desnacionalizados y gobiernos aliados a los grupos más poderosos. En palabras de la autora, el crecimiento necesariamente opera a costa de "empujar gente afuera”.

Se percibe entonces, de un modo único en la historia, cómo las finanzas crecen por sobre las economías. En este sentido avanza el desarrollo del tercer capítulo, "Las finanzas y su capacidad. La crisis como lógica sistémica”, instancia del libro en la cual se realiza una considerable síntesis de la actual internacionalización de los mercados inmobiliarios. Dicha novedad tiene un alcance mundial y se presenta de modo particular en los diferentes países, pero conduce a las mismas degradaciones. En tanto los instrumentos financieros se expanden más rápido que las economías desarrolladas, las crisis se vuelven no sólo recurrentes sino constituyentes del escenario mundial. Dicho proceso es, parafraseando a Saskia, una dinámica conceptualmente subterránea y sólo puede comprenderse reconociendo en la heterogeneidad de los conflictos manifestados en la superficie el accionar de tendencias y lógicas comunes.

Más allá del predominio de las lógicas expuestas, hay un elemento ineludible y pertinentemente destacado por Sassen Saskia: vivimos una era antropocena, alterada fundamentalmente por el accionar del hombre. En relación con ello "Tierra muerta, agua muerta”, cuarto y último capítulo del libro, no sólo enlaza a los dos apartados precedentes, sino que también engloba la temática general de la obra a partir de la lograda exposición de los conflictos definitorios del siglo, tales como desigualdad social, exilio y catástrofes ambientales. Por un lado, se comprende entonces, la importancia de la ya mencionada re-categorización teórica pretendida por la autora, en tanto los problemas están caracterizados por un potencial destructivo 
inédito que no logra ser totalmente descripto a través de concepciones tradicionales. Por otro lado, este capítulo señala el sentido cíclico de los problemas actuales, pues los diferentes desencadenantes están relacionados entre sí, como un espiral creciente e infinito. De este modo indica Sassen cómo los desastres naturales son producto del uso indiscriminado de los recursos en pos del beneficio económico de grupos reducidos, situación generadora de desempleo y más y nuevos pobres. Cada eslabón de esta cadena contiene expulsiones de distinto grado y supera las fronteras aparentemente definitorias.

Por todo esto, Sassen no sólo ofrece un vasto abanico conceptual, valioso por su aporte teórico, sino también invita a pensar a partir de nuevas categorías, necesarias para completar las ausencias en las tradiciones clásicas. Es decir, y como bien aclara la autora, no se deben derribar las definiciones hasta aquí pensadas, pero sí producir ideas congruentes con la complejidad del mundo actual. 